\title{
Social Network Analysis as a Tool for Studying Livelihood Adaptation to Climate Change: Insights from Rural Bangladesh
}

\author{
Ben Nagel ${ }^{1}$ \\ Department of Social Sciences, Leibniz Centre for Tropical Marine Research (ZMT), \\ Bremen, Germany
}

\section{Abstract}

Social network analysis (SNA) is increasingly being applied as a tool for investigating the role of actor ties within social systems, and transparency regarding methodology and fieldwork insights is of importance to this growing field. This paper reviews a study of the rural farming community of East Jelekhali in climate-impacted coastal Bangladesh, where SNA was applied to investigate the role of social network connectivity in household access to climate-adaptive innovative production technologies, such as saline-tolerant rice and high-yielding vegetables, which may provide a means of climate adaptation for agricultural households. Insights are shared on how SNA was applied to map and analyze a community-level livelihood adaptation network. A particular emphasis is made on discussing the benefits, practical applications, and challenges in applying the "whole" network methodology within a community survey-based approach. Methodological limitations and options for future applications of SNA design to climate adaptation research are then presented.

Keywords: Bangladesh, climate change, community adaptation, social network analysis.

\section{Introduction}

There has been increasing interest in the role of social network dynamics in climate adaptation in recent years (Borgatti et al., 2018; Chaudhury et al., 2017; Jaja et al., 2017). Rather than actor outcomes within a climate-impacted community being a function only of that actor's attributes, such as income or education (which may also serve an important role), a social network analysis (SNA) approach posits that an actor's outcomes are to some degree related to the actor's position within

1 Corresponding author: ben.nagel@leibniz-zmt.de. 
a network of relations with other actors (Marin \& Wellman, 2011). Applying SNA to studies of local community dynamics can provide a valuable tool to measure and understand local social support ties and exchanges between households, such as in relation to climate change adaptation. The field of social network research, however, is a relatively new and growing field, where applications of the approach vary between research disciplines and new methods and approaches are constantly in development (Groce et al., 2019; Narayan et al., 2020). This paper contributes to the literature by exploring a case study where survey-based social network design was applied to study the role of local social networks in climate adaptation and access to innovative production technologies (IPT), in this context defined as productionbased livelihood technologies introduced or adopted as climate change adaptive measures. The findings and discussions herein are based on experiences from a master's research project with the Leibniz Centre of Tropical Marine Research in Bremen, Germany, with fieldwork conducted from October 2018 to February 2019 in the community of East Jelekhali in coastal southwest Bangladesh. The primary research objective of this study was to contribute to the growing but incomplete understanding of the relationship between local social networks and access to IPTs by exploring why certain households in a climate-impacted agricultural community engage with these technologies as climate change adaptation strategies, and others do not. The specific objectives of this paper are to (1) explore the background context of the study, (2) detail the social network design methods and analysis applied, (3) discuss lessons learned from this approach in terms of benefits and limitations to the study design, and (4) use this information for future recommendations both in the context of livelihood adaptation, as well as in regards to methodological approaches for applying survey-based SNA.

\subsection{Climate adaptation in Bangladesh}

In coastal Bangladesh, vulnerable rural communities are situated at the frontlines of climate change due to several coalescing factors. Bangladesh is frequently cited as one of the most climate vulnerable countries in the world by organizations such as the World Bank and the Intergovernmental Panel on Climate Change (IPCC) (Ahmed et al., 2017). With a tropical monsoon climate, rainfall variability and flooding have always been a risk to coastal natural resource-dependent communities in Bangladesh (Dasgupta et al., 2011). The frequency and intensity of flooding events, however, has been steadily increasing as a result of climate related factors (Caesar et al., 2015). Climate impacts cited in coastal Bangladesh have included increased occurrences of both flooding and droughts, land and bank erosion, sea level rise, and increased storm surges and severe cyclones, as well as salinity intrusion (Yu et al., 2010). Salinity intrusion has particularly impacted agricultural livelihoods in the coastal zone; it reduces crop production by making land completely uncultivatable, and also contaminates sources of drinking water (Rabbani et al., 2013). In addition, 
river diversions and dams such as the Farakka Barrage have reduced freshwater flow into Bangladesh in the dry season, causing water scarcity and contributing to increased salinity intrusion (Mahmuduzzaman et al., 2014). The expansion of shrimp aquaculture in southwest Bangladesh has also acted as a major contributor to saline water introduction (Tauhid Ur Rahman et al., 2017), adding to an array of growing climate impacts on the predominantly rural agricultural livelihoods in the region.

One of the most frequently proposed ways to adapt agrarian livelihoods to climate change is through innovations in technology and production strategies (Adenle et al., 2015; Lybbert \& Sumner, 2012), which may have the potential to allow agriculture users to continue practicing production-based livelihoods while mitigating climate impacts and reducing vulnerability (Lybbert \& Sumner, 2012). In coastal Bangladesh, a number of IPTs have been identified as climate adaptation measures within local communities, including saline-tolerant rice varieties (Mallick \& Sultana, 2015), homestead vegetable gardens (Uddin et al., 2014), floating agriculture (Chowdhury \& Moore, 2017), and mud crab fattening (K. A. Huq et al., 2015). Nongovernmental organizations (NGOs) and community-based organization development projects have been major drivers in providing IPT resources and training to climate change-impacted regions of rural Bangladesh, particularly at the local scale (Pouliotte et al., 2009). These innovations are adopted not just as general technological improvements, but as "deliberate adaptation measures ... occurred as a result of real or perceived change in the climate condition" - indeed, coastal farmers in Bangladesh have been identified as being highly aware and perceptive of climate change risks (Saha et al., 2016, p. 68). IPTs have the potential to play a critical role in climate risk mitigation by providing viable alternative incomes following disasters and meeting food security needs in areas where environmental change has rendered traditional forms of production unviable (Mallick \& Sultana, 2015).

Within a local community, however, not all climate change-impacted households might have the same access to such IPTs as livelihood adaptations. Households with greater access to financial or physical capital, for example, might have more resources with which to adapt to climate impacts or engage with innovative technologies. While such attributes have often been studied as forms of household capital, less understood is the role of community social relations and social network structures on access to climate-adaptive technologies. Climate adaptation at this local scale is a subject of increasingly emphasized importance in climate change research (Naess, 2013; Rauken et al., 2015). As climate change impacts and socioeconomic conditions tend to be highly variable on a local level, local institutions and communities need to have the capacity to respond to this localized variability if climate change adaptation is to be successful (Laukkonen et al., 2009). Institutional actors such as government organizations and NGOs may play an important driving role in introducing adaptive technologies or facilitating climate change mitigation 
measures through formal training and adaptation networks (Rodima-Taylor et al., 2011). However, rural farming communities are also often heavily dependent on and imbedded in informal social networks, where informal ties between neighbors, friends, and kin allow the exchange of resources and labor to support livelihoods, as well as information and knowledge about adaptation strategies (Eriksen \& Selboe, 2012). To explicitly explore the link between these social networks and climate change adaptation, this study investigated the role of social ties and social network connectivity to household access to IPTs as adaptation strategies in rural southwest Bangladesh, through the framework of SNA.

\subsection{Whole network analysis}

Applying SNA of actors and ties to studies of community dynamics can provide a valuable tool to measure and understand local social support ties and exchanges between households (Cassidy \& Barnes, 2012; Chaudhury et al., 2017), such as in relation to climate adaptation outcomes in the case of this study. To explore how different households with different traits and engagement rates with climate innovations are embedded within a local community social network, a whole network analysis approach was applied in this study. Whole network analysis, as described by Scott and Carrington (2011), involves the complete analysis of all actors and their ties within a given set of network boundaries defined by the research interests. To clarify the whole network approach, it might be best contrasted with another common social network design, the personal or ego network approach, where the focal actor or "ego" is studied, and each ego gives a list of "alters" or ties to others, who are not necessarily studied as separate egos (Borgatti et al., 2018). Whole network design, by including all actors within a given network boundary, allows a broader application of network analysis measures, particularly relating to how network position affects actor outcomes, such as through various network centrality measures (Borgatti et al., 2018).

The whole network approach was applied with a household survey to characterize an entire community adaptation network of all social ties relevant to household livelihood adaptation. The goal was to understand how position within a local community adaptation network relates to individual household attributes and engagement with climate-adaptive technologies, as well as how overall community network structure might impact adaptation. Social interactions between households can have a major influence on long- and short-term decisions by households, such as in decisions to engage with or access particular livelihood strategies (Ettema et al., 2011). Whole network analysis was employed here to quantify social ties in the adaptation network. 
In a rural farming community in southwest Bangladesh, both formal social network connections to external organizational actors and informal ties and exchanges between households in the community were examined to understand how they influence access to IPTs. Primary research questions of the case study included:

1. What social network structures and processes in the local livelihood adaptation network are facilitating or constraining engagement with IPTs?

2. Which types of households engage with IPTs as adaptations to environmental disturbance? Which types of households do not? Why?

It was hypothesized that households with higher connectivity in the community adaptation network would have higher engagement rates with innovative technologies. Position within a community social network has been shown to relate to certain measures of household climate resilience (Cassidy \& Barnes, 2012). I specifically expected that households with a higher degree centrality, or number of direct ties to neighbors, in the network would have higher engagement rates with innovative technologies as climate change adaptive measures (and therefore more climate-resilient livelihoods) than less connected households, through increased access to relevant important social ties for climate adaptation.

\subsection{Study site}

The study was conducted in the community of East Jelekhali, located in the rural subdistrict of Munshiganj Union bordering the Sundarbans mangrove forest in southern Satkhira district, Bangladesh (Figure 1). Local experts identified this region as a climate- and specifically salinity-impacted area where a number of innovations had been adopted by farming communities in response to these stresses. East Jelekhali itself consists of "para" subcommunities of approximately 50 households each, divided primarily based on kinship and family ties. The clear and distinctive social boundaries of these para communities therefore formed the boundaries of the social networks analyzed. Within the study community, the primary research consideration was to complete the household network surveys to obtain the quantitative network data on household livelihood adaptation, as well as on household socioeconomic attributes and engagement with IPTs. Secondary considerations were to incorporate local knowledge into the study through interactions outside of the rigid quantitative survey design. This was accomplished through focus group discussions, key informant interviews, and informal conversations with community members. Through these interactions, I hoped to inform the SNA with a broader contextual understanding of local climate impacts and attitudes; household opinions on various innovative technologies and why households chose to engage or not engage with IPTs. These discussions helped build a narrative on how the community transformed over time in relation to climate impacts and livelihood change. 


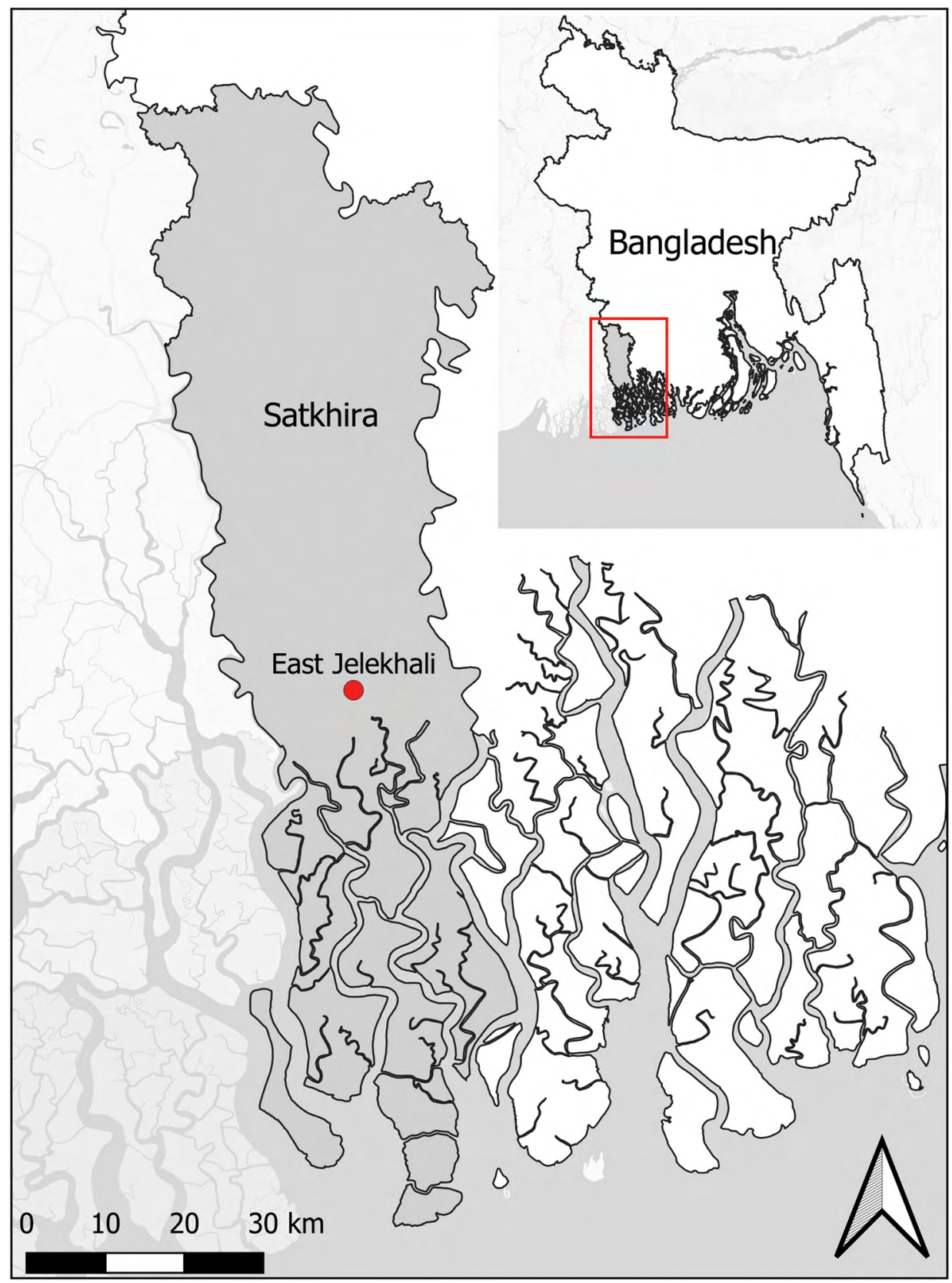

Figure 1. Location of study site: East Jelekhali, Satkhira district, Bangladesh.

Source: Author's representation. 


\section{Methods}

Fieldwork was conducted with three researchers from the Social Science Discipline of Khulna University in the community of East Jelekhali from December 2018 to February 2019. To obtain a detailed overview on topics of climate change, agricultural innovations, and our study site in general, we conducted nine semistructured key informant interviews with local experts, NGO representatives, and selected community members and local opinion leaders. At the study community, actors were identified via "convenience" sampling, based on availability and interest in participating, and selected to represent community members of varying demographics, such as gender, wealth, and status in the community. Topics included: household and community response to and perceptions of climate change; changes in various aspects of household capital before and after environmental disaster; and knowledge of innovative production strategies. Community key informant interviews were conducted in Bangla and transcribed and translated after obtaining permission to record.

In addition, two focus group discussions were conducted with local community members. Each focus group discussion was divided into two parts: a semi-structured discussion and a participatory wealth ranking (PWR) exercise. Participants for each focus group were selected from similar demographics to prevent conflict or dominating voices. This allows different perspectives or stories to emerge from each focus group, as more homogenous groups may limit social barriers to willingness to participate (Onwuegbuzie et al., 2009). Topics of discussion included a timeline of the environmental impact on the community, and demographic-specific climate impacts (such as impacts on farmers and impacts on women). Community perceptions of IPTs were also discussed, as well as perceptions on the major factors facilitating or obstructing access to engagement with the adaptive technologies. By engaging with these topics in a group environment, the discussions aimed to encourage group discourse and interaction to facilitate more detailed and descriptive sharing than in individual community member interviews. It also allowed us to identify areas of consensus and conflict on discussion topics. The second part of the focus group consisted of a PWR activity, following the framework of existing PWR methods in the literature (Coirolo \& Rahman, 2014; Committee on Sustainability Assessment, 2015). PWR is typically a measure of relative poverty that allows community members to assess the community themselves, based on their own definitions of poverty (Zeller et al., 2006). Participants were asked to discuss households in terms of four categories of relative wealth: "wealthy," "moderately well-off," "poor," and "very poor." To assign households to each of these rankings, participants were first asked to form a consensus on the major indicators of each of these wealth categories, after which participants assigned each household to the relevant category. Household 
social network connectivity and innovation engagement could then be compared with these wealth scores. Definitions of wealth categories as defined by community members can be found in Table 1.

Table 1. Participatory wealth ranking (PWR) categories. Wealth categories and key indicators as determined by community focus group participants.

\begin{tabular}{|l|l|}
\hline Category & Key identifiers \\
\hline Wealthy & $\begin{array}{l}\text { Large landowners/farmers with over 1,000 decimals of land (100 decimals = } \\
\text { approximately 1 acre), or households with a high status job, including large } \\
\text { business owners, doctors, and government workers. Have highest education level, } \\
\text { and often lease out land to other households. }\end{array}$ \\
\hline $\begin{array}{l}\text { Moderately } \\
\text { well-off }\end{array}$ & $\begin{array}{l}\text { Medium-scale farmers, most of which own or rent farmland in the range of 500-750 } \\
\text { decimals. Some lease out land to other households. May have some household } \\
\text { members engaged with small business, but are not large business owners. }\end{array}$ \\
\hline Poor & $\begin{array}{l}\text { Primarily farmers who own or rent some land, but very little. No more than 100-200 } \\
\text { decimals. Dependence on wealthier households often necessary, for example as } \\
\text { sharecroppers. }\end{array}$ \\
\hline Very poor & $\begin{array}{l}\text { Households which are either landless or own only house land. Farmers } \\
\text { (sharecroppers) and non-agricultural laborers. No cash money typically, and } \\
\text { high dependence on wealthier households. }\end{array}$ \\
\hline
\end{tabular}

Source: Author's summary of focus group discussion findings.

In addition to households within each para, we also included external organizations (such as NGOs or community organizations) identified by community members as playing an important role in introducing or otherwise supporting engagement with IPTs. Households, rather than individuals, within the community form the primary actors of interest to this research, based on the understanding that climate change adaptation decisions are typically made at the household rather than individual level (Thomas et al., 2007). Also, individual livelihood outcomes and resilience are strongly related to the overall household's livelihood strategy (Sallu et al., 2010). To obtain social network and household attribute data, a survey and social network questionnaire was conducted with every household within the network boundaries. Due to the study timeline overlapping with a busy harvest season, convenience sampling was utilized, selecting a representative from each household based on availability and willingness to participate. To obtain network data, each respondent was asked about which households or organizations have played an important role in adapting their household's livelihood to the changing environmental conditions. The network data focused on the ties important for adapting to or mitigating climate impacts, creating the basis for visualizing a "livelihood adaptation" network within the community. As adaptation strategies are not limited to innovation, the survey did not exclude "non-innovation" households. To help reduce recall error, the "roster recall" method of social network data collection, as described by Borgatti et al. (2018), was employed for generating household ties. Each household informant worked through a roster of all households in the community, identifying and characterizing all social ties that they considered important for their household's 
ability to adapt to climate change. The primary advantage of this data collection method is a reduction in recall error by respondents, although using this method can become impractical with increasing sample sizes where the large number of actors in the network can become unwieldy. After a respondent completed a list of actors for the network question, a series of follow-up questions was asked about each actor, to define the attributes of each tie (such as "information" or "money"). Rather than using predetermined tie categories, this question was left open-ended for the respondent to define the type of interaction, in order to account for the possibility of important tie categories not predicted by the researcher. The direction of the tie was also categorized, allowing for the creation of a "directed" social network.

In addition to collecting social tie data, we surveyed general household attributes such as data on the household respondent, primary and additional livelihoods in the household, changes to household livelihoods as a result of the environmental impacts, and household engagement with and knowledge of innovative technologies. The household survey also included the Poverty Probability Index (PPI), a questionnaire developed by the Grameen Foundation and currently managed by Innovations for Poverty Action (IPA) as a tool to measure household or community poverty (Innovations for Poverty Action, n.d.). The questionnaire aims to estimate poverty levels with simple multiple-choice questions about household traits and assets. The PPI is cited in a number of applications in the non-profit and research field as an effective poverty measuring tool (Committee on Sustainability Assessment, 2015; Desiere et al., 2015), and in this context allowed for a secondary wealth measuring tool in addition to the participatory methods.

\subsection{Data analysis}

Applying survey and interview methods made it possible to combine qualitative community member insights with quantitative social network data. Interview and focus group data was primarily applied as qualitative descriptive information and used to provide background context about the study community. It was also used to corroborate findings from the SNA. Descriptive statistics of community demographic data, IPT engagement, and other household attributes were calculated from household survey data. For this analysis, network measures were calculated using the SNA program UCINET 6 (Borgatti et al., 2002). Node-level network measures analyzed included degree centrality (the household's direct connections to other actors) and betweenness centrality (the number of times a household lies on the shortest path between two other actors). Degree centrality was selected both due to its prevalence in the literature (Bodin et al., 2006; Cassidy \& Barnes, 2012), allowing a greater degree of comparability, but also its relative robustness to various sampling conditions and errors compared to other network measures (Wang et al., 2012). Betweenness centrality allowed for a measure of indirect influence within the network, such as a critical actor controlling the flow of information from one part 
of the network to another (who might not otherwise have a high degree centrality). As directed tie data was collected, in-degree centrality and out-degree centrality were also included in the analysis to allow for a more granular analysis of degree centrality. For example, it might be expected that innovation engagement relates to a higher number of incoming support ties. Node-level network measures were analyzed using the UCINET 6 routine "Network>Centrality>Multiple Measures."

\section{Results}

In this section, I discuss initial results gathered from one of the East Jelekhali study paras, Mondol, in order to frame the following discussion on insights from applying SNA. Within the Mondol study community, households had adopted four primary IPT categories as adaptations to local climate stresses, particularly salinity intrusion and rainfall variability, described in Table 2 . Overall engagement rates with these innovations was quite high, with 87 percent of Mondol households engaged with at least one IPT. All households that engaged with the technologies reported positive benefits to the household, with the most reported benefits being increased income and food production. Figure 2 displays the livelihood adaptation network that was mapped in the Mondol community. Household interviews and focus groups in Mondol described the livelihood innovations as primarily being adopted in the aftermath of the devastating impacts of Cyclone Aila in 2009, when salinity intrusion and flooding in the community worsened.

Table 2. Innovative production technologies (IPTs) in Mondol para.

\begin{tabular}{|l|l|}
\hline Innovation & Description \\
\hline Saline-tolerant rice & $\begin{array}{l}\text { Salinity-tolerant rice varieties which help offset production losses due } \\
\text { to increased soil salinity, particularly in the dry "boro" growing season. }\end{array}$ \\
\hline Homestead gardens & $\begin{array}{l}\text { Historically not commonly practiced in Mondol, training on cultivation } \\
\text { of saline-tolerant and high-yielding vegetable varieties was provided to } \\
\text { households by local NGOs as a climate-adaptive livelihood strategy. }\end{array}$ \\
\hline Multiuse fish ponds & $\begin{array}{l}\text { As local climate conditions changed, some households started engaging } \\
\text { in extensive carp aquaculture as a supplementary nutrition and income } \\
\text { source in preexisting multiuse ponds also used for washing and bathing. }\end{array}$ \\
\hline Hanging gardens & $\begin{array}{l}\text { Through NGO training, households constructed low-cost bamboo frames } \\
\text { and hanging nets via which vine-like vegetables such as cucumber and } \\
\text { squash could be grown with reduced impact from waterlogging, and as } \\
\text { a second layer of production over ponds or gardens. }\end{array}$ \\
\hline
\end{tabular}

Source: Author's summary of fieldwork results.

Network results help identify the social structures and processes facilitating engagement with innovative technologies in Mondol. The majority of respondents identified the knowledge and training on how to practice these IPTs as originating outside the community, from NGO training and workshops, rather than government intervention. This is corroborated by the Mondol network diagram 
(Figure 2) which shows that eight NGOs were involved in the livelihood adaptation network, with NGOs 1 and 3 playing a particularly central role, for which the ties primarily consisted of formal training and microloans. In addition to formal training ties from NGOs, the network visualization also shows a dense network of support ties between households, which included informal household information sharing, moneylending, and labor exchange ties important for livelihood adaptation. Indeed, while NGOs were identified as the source of knowledge on the IPTs in Mondol, half of the households reported learning how to practice the innovations from neighbors, as knowledge diffused from households with direct NGO training ties to neighboring households.

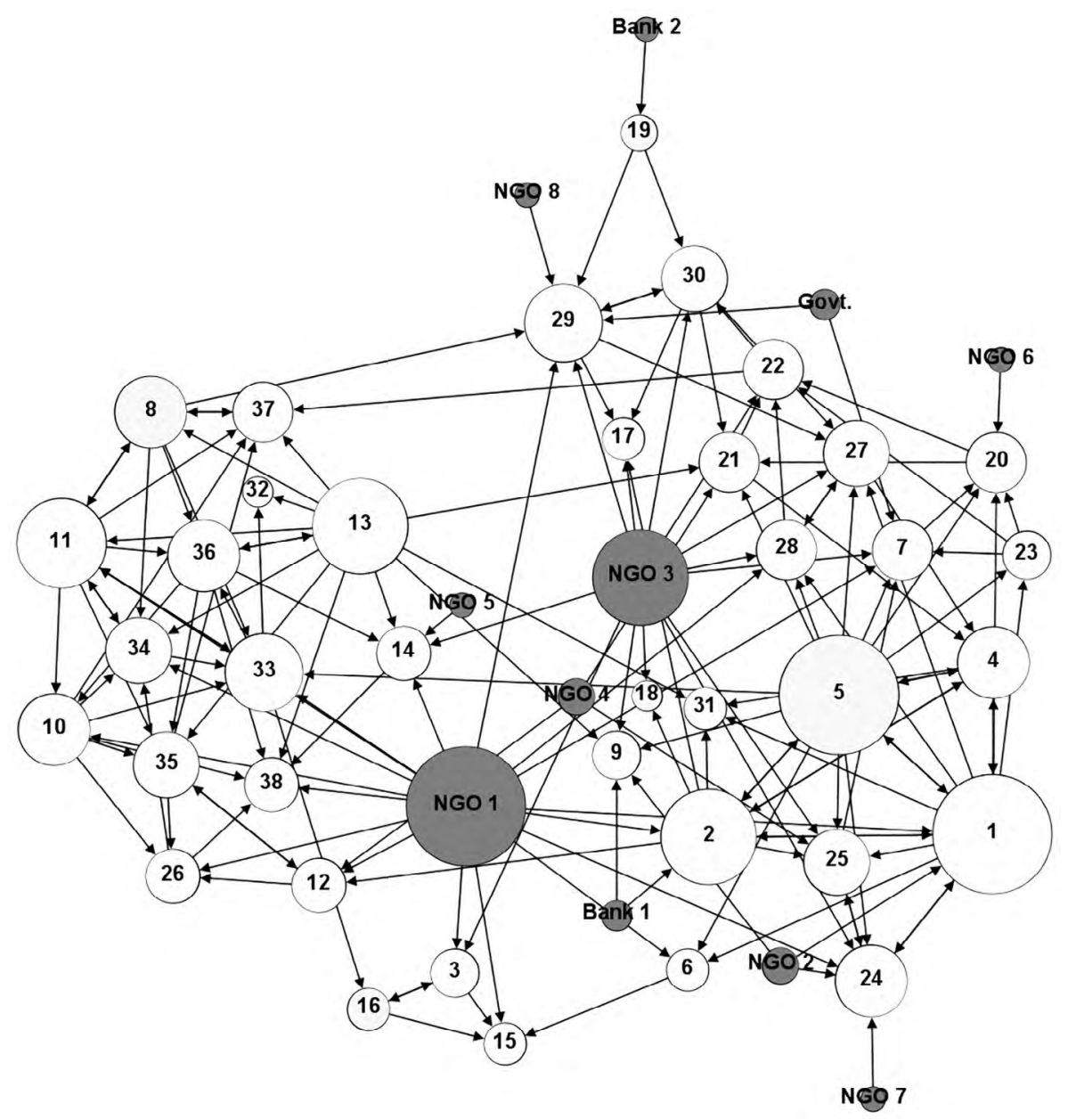

Figure 2. Mondol network of social ties important for livelihood adaptation to climate change.

Note: Households in white, external organization actors in gray. Size of node represents degree centrality. Numbers correspond to randomly assigned actor IDs.

Source: Author's representation. 
Of particular relevance to this analysis were the node-level associations between innovation engagement and social network position. Different tie categories within a network are often analyzed as separate individual networks (Cassidy \& Barnes, 2012), so separate component networks were mapped and analyzed for the three most frequently reported tie categories: information, money, and labor. Engagement with innovative technologies was analyzed as the number of innovative technologies being practiced within the household. Research shows a strong association between livelihood diversity and climate resilience (Cassidy \& Barnes, 2012), and it was expected that households with greater connectivity within a social network of adaptive support ties would be more likely to have a greater diversity of climate-adaptive IPTs present, forming at least one indicator of household resilience. It might also be assumed that household wealth is a driving factor in household engagement with agricultural innovations, so associations between household wealth, as measured by both of our wealth-scoring methods, and innovation engagement were also analyzed.

An initial step in analyzing associations between network centrality and innovation engagement and wealth was in applying correlation coefficients. An example of these correlations for the Mondol study community is provided in Table 3. Results showed a significant relationship between innovation engagement and network position specifically in terms of in-degree centrality, which was significant in both the overall network $(0.290, p=0.030)$ and the information network $(0.286, p=0.033)$, suggesting a link between amount of incoming climate-adaptive information and access to innovative technologies. An additional relationship was found between network centrality and wealth, particularly with community-defined PWR wealth categories, where there was a significant relationship between wealth and both degree and out-degree centrality in all component networks. In Mondol, wealthier households tend to occupy more central roles within the community network, particularly acting as a primary source of outgoing social ties to neighboring community members. PWR wealth score was also found to be significantly positively correlated with household innovation engagement $(0.284, p=0.047)$.

Table 3. Correlation coefficients between network centrality and household traits.

\begin{tabular}{|l|c|c|c|}
\hline & Innovation engagement & PPI & PWR \\
\hline Degree-Information & 0.119 & 0.056 & $\mathbf{0 . 3 7 6}$ \\
\hline Degree-Money & 0.116 & 0.199 & $\mathbf{0 . 2 6 5}$ \\
\hline Degree-Labor & 0.077 & $\mathbf{0 . 2 6 4}$ & $\mathbf{0 . 2 4 1}$ \\
\hline Degree-Overall & 0.081 & 0.227 & $\mathbf{0 . 4 1 2}$ \\
\hline In-Degree-Information & $\mathbf{0 . 2 8 6}$ & -0.051 & 0.148 \\
\hline In-Degree-Money & 0.006 & -0.041 & -0.169 \\
\hline In-Degree-Labor & 0.134 & 0.153 & -0.047 \\
\hline In-Degree-Overall & $\mathbf{0 . 2 9 0}$ & -0.023 & -0.028 \\
\hline
\end{tabular}




\begin{tabular}{|l|c|c|c|}
\hline & Innovation engagement & PPI & PWR \\
\hline Out-Degree-Information & -0.086 & 0.118 & $\mathbf{0 . 4 0 9}$ \\
\hline Out-Degree-Money & 0.111 & $\mathbf{0 . 2 6 4}$ & $\mathbf{0 . 5 0 9}$ \\
\hline Out-Degree-Labor & -0.136 & $\mathbf{0 . 2 5 7}$ & $\mathbf{0 . 3 4 1}$ \\
\hline Out-Degree-Overall & -0.078 & $\mathbf{0 . 2 3 6}$ & $\mathbf{0 . 4 6 9}$ \\
\hline Betweenness-Information & 0.069 & 0.079 & $\mathbf{0 . 3 9 7}$ \\
\hline Betweenness-Money & 0.11 & 0.095 & 0.19 \\
\hline Betweenness-Labor & -0.011 & 0.158 & 0.185 \\
\hline Betweenness-Overall & -0.072 & 0.164 & 0.243 \\
\hline
\end{tabular}

Note: Kendall's tau-b correlation coefficients. Bold results are significant at or below $p=0.1$. PPI $=$ Poverty Probability Index scores. Higher scores represent lower risk of poverty. PWR = Participatory Wealth Ranking scores. Higher scores represent higher wealth.

Source: Author's summary of fieldwork results.

To determine the role of household in-degree centrality and PWR wealth on innovation diversity, permutation-based regression analysis was applied. While traditional inferential regression tests draw on assumptions that data is derived from a random sample with a certain distribution, SNA deals with datasets that represent an entire population (Borgatti et al., 2018). In addition, traditional inferential tests assume that observations are statistically independent, while social network data is by nature non-independent, as the existence of ties for one node necessitates at least one other node having a tie as well (Krackhardt, 1988). Social network data, therefore, is not particularly compatible with such traditional statistical methods, at least in terms of assigning confidence to results. As described by Borgatti et al. (2018), permutation testing allows investigation of the likelihood that significant network findings were due to random chance alone, by comparing observed correlations to the distribution of correlations that would be obtained if the variables were truly independent. To analyze regression results of Mondol, the permutation testing utility in UCINET 6 was applied ("Tools $>$ Testing Hypotheses>Nodelevel>Regression"), which computes classic linear multiple regression results, and estimates significance through random permutations (Hanneman \& Riddle, 2005). The results of this method for the Mondol community are provided in Table 4, where in-degree centrality (In-degree) and PWR wealth scores (Wealth) were investigated as independent variables and innovation engagement as the dependent variable. In total, 10,000 random permutations were run. For more in-depth reading on applications of permutation tests in social networks, see Chapter 8 of Borgatti et al. (2018) and Boyd et al. (2006). Butts (2008) describes SNA with the "sna" $\mathrm{R}$ package, including permutation testing. 
Table 4. Network regression permutation test results. Probability based on randomization tests.

\begin{tabular}{|c|c|c|c|c|c|}
\hline & Wealth & In-degree & Innovation & & \\
\hline Wealth & 1.000 & -0.068 & 0.293 & & \\
\hline In-degree & -0.068 & 1.000 & 0.330 & & \\
\hline Innovation & 0.293 & 0.330 & 1.000 & & \\
\hline \multicolumn{6}{|c|}{ Determinant $=0.99544232$} \\
\hline \multicolumn{6}{|l|}{ Model Fit } \\
\hline $\mathbf{R}^{2}$ & Adjusted $\mathbf{R}^{2}$ & F Value & Probability & & \\
\hline 0.209 & 0.161 & 4.361 & 0.022 & & \\
\hline \multicolumn{6}{|c|}{ Regression Coefficients } \\
\hline Independent & $\begin{array}{l}\text { Unstandardized } \\
\text { coefficient }\end{array}$ & $\begin{array}{c}\text { Standarized } \\
\text { coefficient }\end{array}$ & $\begin{array}{l}\text { Proportion } \\
\text { as Large }\end{array}$ & $\begin{array}{c}\text { Proportion } \\
\text { as Small }\end{array}$ & $\begin{array}{l}\text { Proportion } \\
\text { as Extreme }\end{array}$ \\
\hline Intercept & 0.144 & 0.000 & 0.000 & 0.000 & 0.000 \\
\hline Wealth & 0.339 & 0.327 & 0.032 & 0.968 & 0.062 \\
\hline In-degree & 0.250 & 0.352 & 0.017 & 0.983 & 0.034 \\
\hline
\end{tabular}

Source: Author's summary of permutation test results.

The correlation matrix shows once again that wealth and in-degree are positively correlated with innovation diversity (but not particularly correlated with each other). The $\mathrm{R}^{2}$ value is 0.209 , which was higher than similar models run using only wealth or in-degree alone as the independent variable. In permutation testing, the probability value represents the likelihood that the results are due to random chance alone. In this case, the probability is highly significant (one-tailed $p=0.022$ ), suggesting that the findings are not due to random chance. Controlling for other variables, the standardized coefficients show that both household indegree and wealth are positively and significantly related to household innovation diversity, with in-degree having a slightly larger effect $(0.352, p=0.017)$ than wealth $(0.327, p=0.032)$. By using this permutation testing method, I can establish some support for the case study hypothesis, in this case that households with a higher in-degree centrality in the local livelihood adaptation network are more likely to be engaged with a higher number of climate-adaptive innovations. While there are certainly a multitude of factors at play in determining household engagement with innovations as climate adaptations, these results provide an important first step in establishing a link between social networks and household climate adaptation via innovative livelihood strategies. 


\section{Lessons learned from study tools}

\subsection{Network questionnaire and household survey}

Network-based surveys can often be a tiresome experience for both translator and respondent, as repetitive questions are continually asked about each social tie reported by the respondent. Additionally, in the roster recall method an entire list of network actors must be referenced one by one with the respondent. Survey-based network design can thus unsurprisingly be prone to a number of types of errors during data collection (Scott \& Carrington, 2011). Attempts were made to reduce the burdensome nature of such surveys on both the research team and respondents. Questions about social ties were kept only to the critical relevant topics necessary for the research, to reduce the time requirements to describe each social tie. Some researchers emphasize that the placement of network questions in a survey may affect outcomes. For example, cognitively intensive network questions asked at the end of an already intensive survey might increase non-response error (Borgatti et al., 2018). By pretesting our surveys within the study area, however, our team found that first collecting household survey data before asking network questions resulted in greater respondent engagement. As the household survey gradually introduced research topics individually, such as local climate change impacts or IPTs, translators could gauge the respondent's understanding of the topics before we moved to the network questions. By that time, the respondent also had a clearer idea of the categories of ties being solicited by the network questionnaire.

The network questionnaire as designed included prompts asking for not only beneficial ties but obstructing ties as well. While such ties were not expected to be reported between households due to the sensitive nature of discussing such topics with outsiders, its inclusion was considered important due to the potential of obstructing ties from government, NGO, or other outside actors. This question was de-emphasized during surveys, however, when it became obvious that respondents were generally uncomfortable discussing obstructive ties. In general, it is important to assess the sensitivity and potential risk of network questions to respondents, as network data is often not truly anonymous. Further discussion on ethical issues in SNA can be found in the literature (Borgatti \& Molina, 2003; Kadushin, 2005). It is worth noting the importance of careful planning and respondent prompting in cataloging the reported social ties by each respondent in a survey-based design. In our case study, a household roster was used and a random number assigned to every household. Households were primarily reported by the name of the head of household by respondents, but there were many cases of heads of households with the same names or respondents reporting ties to someone other than the head of household. The time-intensive nature of a roster-based household survey could result in frequent reporting errors due to such inconsistencies, and frequent return trips were made to households in this case study to verify answers. 


\subsection{Interviews and focus groups}

As fieldwork dates overlapped with a busy harvest season, time allotted to lengthy interviews and focus group discussions was limited. Local farmer insight into the environmental changes on agricultural livelihoods heavily informed the background context of the study and helped to inform further questions or discussion topics to add to household surveys. Focus group discussions in the community were particularly successful. Careful attention was paid in trying to group respondents based on similar demographics, and to reduce the likelihood of participants deferring toward a more dominant voice in the discussions. The research team attempted to ask questions that promoted discussion and consensus-making among the focus group participants. This often resulted in participants engaging the researchers with their own inquiries. This was also successful during our PWR (participatory wealth ranking) exercise, where respondents formed a consensus on the wealth category of each household after a short discussion.

\subsection{Fieldwork insights}

Of further value to this study were informal visits and walkthroughs of the study community. These visits proved important for several reasons. Spending time in the community before or after surveys allowed for community members to engage the researchers at their own discretion with questions or inquiries. Some key informant interviews and critical topics within the community were uncovered this way, where our presence in the community outside of surveys allowed for more informal interactions and conversations. In addition, walks through the community with locals proved the best way to learn about the different IPTs present in the area. Observing various innovations with a community member allowed for a more natural discussion on the technologies and their relevance to the community. Further discussion on transect walks as a participatory study tool can be found in Kanstrup et al. (2014).

The importance of including local perspectives and research expertise when conducting research in a study community as a foreigner should always be emphasized. The fieldwork team in this study consisted of the author, from a foreign institute, and three local graduate-level students with research experience. This team acted not only as data collectors and translators but contributed a local cultural context, perspective, and awareness that could not be provided by the lead foreign researcher. Local researchers also helped to initially approach and disarm respondents, establishing a friendly and conversational tone. Emphasis was placed on not only providing direct translations of responses, but also picking up on tone and social cues that might further inform the response. This was particularly important in our case study due to the sensitive nature of network questions, where slight differences in researcher tone or phrasing might elicit different social tie 
responses from the respondent. Translations of network surveys were worked on collaboratively as a study team, and initial household surveys were conducted as a group to ensure consistency, before translators split up to survey independently. We also attempted to keep translations and questions conversational and avoided heavy usage of formal scientific terminology. Frequent meetings throughout the field day and at the end of day allowed the team to discuss any issues or topics of interest that warranted addressing.

\section{Conclusion}

This case study review demonstrates that applying SNA in the field carries its own set of challenges, along with beneficial insights. Survey-based network analysis methods themselves can often be exhausting for both researcher and respondent, with potential impacts on data quality. The cultural and community context and the nature of the researcher-respondent relationship must also be taken to account when attempting to elicit ties of a potentially sensitive nature. There needs to be an emphasis on discussing the potential lack of anonymity in social network results, and what that might mean for the respondent. In East Jelekhali, SNA allowed us to explore the potential role of household social networks on access to innovative technologies which have become a primary means of livelihood adaptation in climate-impacted coastal regions of Bangladesh (Saha et al., 2016). In this case, ties to NGOs provided formal training and moneylending to support household engagement with these activities. However, equally important were informal ties between households, through which the knowledge and training on these IPTs diffused and crucial labor and money exchanges provided support. Analysis of network data showed that of the variables collected, in-degree centrality was most significantly associated with innovation engagement in households, suggesting further need to explore the role of social network position in climate adaptation and resilience. While this study analyzed associations between various household traits and network measures, determining causality in SNA is difficult to unravel, as discussed in detail by Doreian (2001). These results provide an initial step in establishing a relationship between network position, socioeconomic traits, and innovation engagement within a rural agricultural community, but the study does not attempt to fully uncover all causal mechanisms present.

The results of this study suggest potential for further methodological development of SNA. While applications of SNA provide some insight into potential relationships between network centrality and livelihood adaptation, causal forces in social networks are difficult to investigate with such cross-sectional studies. In that respect, future scholarly SNA investigations need to emphasize developing ethical and practical social experiment methodologies to truly and accurately capture the nature of these complex networks and move the field of SNA research forward. Adding a temporal 
component to a community network analysis, such as investigating the adaptation networks soon after an environmental disaster and after adaptive strategies have disseminated through the community, might also paint a clearer picture of the relationships identified in this study. Static social network diagrams do not adequately demonstrate the dynamic nature of networks and social ties, and a study incorporating time-series network data might elucidate how networks evolve over time. I also emphasize the inclusion of participatory methods where appropriate, ideally allowing for active participation of locals in steering and shaping the research goals and questions, particularly in intercultural contexts where such methods can develop a greater understanding between researcher and participants (Schiffer \& Hauck, 2010). Social network methods such as net-mapping (Schiffer \& Hauck, 2010), which was not included in this study due to unexpected time limitations, may be highly valuable in this regard, allowing for group participatory consensusmaking on the selection of relevant actors and measuring perceptions of influence of various network actors. While there has been a rapid growth in SNA research in the literature in recent years, the potential, and challenges, of applying network research in the field has not yet been fully explored. Hopefully, these insights can inform other new researchers on potentially common challenges to social network field design and methodology, and instigate new ideas in applying SNA toward livelihood adaptation research.

In the context of climate vulnerable regions such as rural coastal Bangladesh, we have investigated the potential link between community social network position and engagement with innovative technologies as adaptation measures which have provided broad quality-of-life improvements in areas severely impacted by saline soils. However, while these innovations play an important role in providing food security and income to agricultural livelihoods, innovation engagement is itself a very limited definition of climate change adaptation. Numerous climate changeinduced factors which agricultural innovations cannot account for are shaping the vulnerability of rural livelihoods, ranging from the direct physical damage and flooding of increasing severe storm events (including the recent devastation of Cyclone Amphan in May 2020) to illness from water contamination (Shameem et al., 2014). As researchers, further applications of network analysis may help understand climate adaptation processes at levels beyond the scale of communitylevel household networks. As shown in Mondol, NGOs in Bangladesh are often playing a leading role in disaster response and climate adaptation projects, with over 40 NGOs actively registered as of 2020 in Khulna Division alone (Bangladesh National Portal, 2021). At a regional scale, SNA may provide a valuable research tool to explore communication, coordination, and areas of potential synergy within NGO social networks in Bangladesh to improve NGO response to climate disasters. Additionally, rural to urban migration is an increasing response to coastal climate disasters in Bangladesh (N. Huq et al., 2015). Migration brings with it inherent risks 
and vulnerabilities, both for those migrating and the family members left behind, and SNA of both of these groups might allow for a better understanding of climate migration outcomes.

\section{Acknowledgments}

I would first like to thank the community of East Jelekhali, whose people were gracious and friendly in sharing their knowledge and time with us. I would also like to thank Abir Hassan, Baizid Mahmud, and Karimun Nessa, from Khulna University who conducted all the Bengali-language data collection for this study, for their dedication and friendship. Finally, my thanks to Eike Holzkämper and Marion Glaser from the Leibniz Centre for Tropical Marine Research as well as Samiya Selim from the Center for Sustainable Development, University of Liberal Arts Bangladesh, for their support, advice, and supervision.

\section{References}

Adenle, A. A., Azadi, H., \& Arbiol, J. (2015). Global assessment of technological innovation for climate change adaptation and mitigation in developing world. Journal of Environmental Management, 161, 261-275. doi.org/10.1016/j.jenvman.2015.05.040

Ahmed, A. U., Mondal, P., \& Islam, M. (2017). Community-based adaptation: An analysis of best practices in the south-western region of Bangladesh. CARE Bangladesh. www.care bangladesh.org/upload/files/publication_1524050576_2.pdf

Bangladesh National Portal. (2021). List of all NGOs. Retrieved March 2, 2021, from ngoab.portal.gov.bd/site/page/3de95510-5309-4400-97f5-0a362fd0f4e6/-

Bodin, Ö., Crona, B., \& Ernstson, H. (2006). Social networks in natural resource management: What is there to learn from a structural perspective? Ecology and Society, 11(2), Response 2. doi.org/10.5751/ES-01808-1102r02

Borgatti, S. P., Everett, M. G., \& Freeman, L. C. (2002). UCINETfor Windows (Version 6.715) [Computer software]. Analytic Technologies. sites.google.com/site/ucinetsoftware/home

Borgatti, S. P., Everett, M. G., \& Johnson, J. C. (2018). Analyzing social networks (2nd ed.). SAGE Publications.

Borgatti, S. P., \& Molina, J. L. (2003). Ethical and strategic issues in organizational social network analysis. The Journal of Applied Behavioral Science, 39(3), 337-349. doi.org/ $10.1177 / 0021886303258111$

Boyd, J. P., Fitzgerald, W. J., \& Beck, R. J. (2006). Computing core/periphery structures and permutation tests for social relations data. Social Networks, 28(2), 165-178. doi.org/ 10.1016/j.socnet.2005.06.003 
Butts, C. T. (2008). Social network analysis with sna. Journal of Statistical Software, 24(6). doi.org/10.18637/jss.v024.i06

Caesar, J., Janes, T., Lindsay, A., \& Bhaskaran, B. (2015). Temperature and precipitation projections over Bangladesh and the upstream Ganges, Brahmaputra and Meghna systems. Environmental Science: Processes \& Impacts, 17(6), 1047-1056. doi.org/10.1039/ C4EM00650J

Cassidy, L., \& Barnes, G. D. (2012). Understanding household connectivity and resilience in marginal rural communities through social network analysis in the village of Habu, Botswana. Ecology and Society, 17(4), Article 11. doi.org/10.5751/ES-04963-170411

Chaudhury, A. S., Thornton, T. F., Helfgott, A., Ventresca, M. J., \& Sova, C. (2017). Ties that bind: Local networks, communities and adaptive capacity in rural Ghana. Journal of Rural Studies, 53, 214-228. doi.org/10.1016/J.JRURSTUD.2017.05.010

Chowdhury, R. B., \& Moore, G. A. (2017). Floating agriculture: A potential cleaner production technique for climate change adaptation and sustainable community development in Bangladesh. Journal of Cleaner Production, 150, 371-389. doi.org/ 10.1016/j.jclepro.2015.10.060

Coirolo, C., \& Rahman, A. (2014). Power and differential climate change vulnerability among extremely poor people in northwest Bangladesh: lessons for mainstreaming. Climate and Development, 6(4), 336-344. doi.org/10.1080/17565529.2014.934774

Committee on Sustainability Assessment (COSA). (2015). Testing the Progress out of Poverty Index: Update to 2013-2014 report. thecosa.org/wp-content/uploads/2015/04/TestingProgress-Out-of-Poverty-Synthesis-Update-Report-..pdf

Dasgupta, S., Huq, M., Khan, Z. H., Masud, S., Murshed, M., Mukherjee, N., \& Pandey, K. (2011). Climate proofing infrastructure in Bangladesh: The incremental cost of limiting future flood damage. The Journal of Environment \& Development, 20(2), 167-190. doi.org/ $10.1177 / 1070496511408401$

Desiere, S., Vellema, W., \& D’Haese, M. (2015). A validity assessment of the Progress out of Poverty Index (PPI) ${ }^{\mathrm{TM}}$. Evaluation and Program Planning, 49, 10-18. doi.org/10.1016/ j.evalprogplan.2014.11.002

Doreian, P. (2001). Causality in social network analysis. Sociological Methods \& Research, 30(1), 81-114. doi.org/10.1177/0049124101030001005

Eriksen, S., \& Selboe, E. (2012). The social organisation of adaptation to climate variability and global change: The case of a mountain farming community in Norway. Applied Geography, 33, 159-167. doi.org/10.1016/J.APGEOG.2011.10.003

Ettema, D., Arentze, T., \& Timmermans, H. (2011). Social influences on household location, mobility and activity choice in integrated micro-simulation models. Transportation Research Part A: Policy and Practice, 45(4), 283-295. doi.org/10.1016/J.TRA.2011.01.010 
Groce, J. E., Farrelly, M. A., Jorgensen, B. S., \& Cook, C. N. (2019). Using social-network research to improve outcomes in natural resource management. Conservation Biology, 33(1), 53-65. doi.org/10.1111/cobi.13127

Hanneman, R. A., \& Riddle, M. (2005). Introduction to social network methods [Digital publication]. University of California, Riverside. faculty.ucr.edu/ -hanneman/nettext/

Huq, K. A., Rahaman, S. M. B., \& Hasanuzzaman, A. F. M. (2015). Mud crab culture as an adaptive measure for the climatically stressed coastal fisher-folks of Bangladesh. In C. Finkl \& C. Makowski (Eds.), Coastal research library: Vol 8, Environmental management and governance-advances in coastal and marine resources (pp. 175-198). Springer Nature. doi.org/10.1007/978-3-319-06305-8_7

Huq, N., Hugé, J., Boon, E., \& Gain, A. K. (2015). Climate change impacts in agricultural communities in rural areas of coastal Bangladesh: A tale of many stories. Sustainability, 7(7), 8437-8460. doi.org/10.3390/su7078437

Innovations for Poverty Action (IPA). (n.d.). About the PPI: A poverty measurement tool. Retrieved June 12, 2019, from www.povertyindex.org/about-ppi

Jaja, J., Dawson, J., \& Gaudet, J. (2017). Using social network analysis to examine the role that institutional integration plays in community-based adaptive capacity to climate change in Caribbean small island communities. Local Environment, 22(4), 424-442. doi.org/10.1080/13549839.2016.1213711

Kadushin, C. (2005). Who benefits from network analysis: Ethics of social network research. Social Networks, 27(2), 139-153. doi.org/10.1016/J.SOCNET.2005.01.005

Kanstrup, A. M., Bertelsen, P., \& Madsen, J. Ø. (2014, October). Design with the feet: Walking methods and participatory design. In PDC '14: Proceedings of the 13th participatory Design Conference, Windhoek, Namibia, 1, 51-60. Association for Computing Machinery (ACM). doi.org/10.1145/2661435.2661441

Krackhardt, D. (1988). Predicting with networks: Nonparametric multiple regression analysis of dyadic data. Social Networks, 10(4), 359-381. doi.org/10.1016/0378-8733 (88)90004-4

Laukkonen, J., Blanco, P. K., Lenhart, J., Keiner, M., Cavric, B., \& Kinuthia-Njenga, C. (2009). Combining climate change adaptation and mitigation measures at the local level. Habitat International, 33(3), 287-292. doi.org/10.1016/J.HABITATINT.2008.10.003

Lybbert, T. J., \& Sumner, D. A. (2012). Agricultural technologies for climate change in developing countries: Policy options for innovation and technology diffusion. Food Policy, 37(1), 114-123. doi.org/10.1016/J.FOODPOL.2011.11.001

Mahmuduzzaman, M., Ahmed, Z. U., Nuruzzaman, A. K. M., \& Ahmed, F. R. S. (2014). Causes of salinity intrusion in coastal belt of Bangladesh. International Journal of Plant Research, 4(4A), 8-13. article.sapub.org/10.5923.s.plant.201401.02.html 
Mallick, B., \& Sultana, Z. (2015). Adaptation strategies after cyclone in southwest coastal Bangladesh-pro-poor policy choices. American Journal of Rural Development, 3(2), 24-33. doi.org/10.12691/ajrd-3-2-2

Marin, A., \& Wellman, B. (2011). Social network analysis: An introduction. In J. Scott \& P. J. Carrington (Eds.), The SAGE handbook of social network analysis (pp. 11-25). SAGE Publications. mis.csit.sci.tsu.ac.th/siraya/wp-content/uploads/2015/09/1SocialNetwork-Analysis-An-Introduction-1.pdf

Naess, L. O. (2013). The role of local knowledge in adaptation to climate change. Wiley Interdisciplinary Reviews: Climate Change, 4(2), 99-106. doi.org/10.1002/wcc.204

Narayan, A. S., Fischer, M., \& Lüthi, C. (2020). Social network analysis for water, sanitation, and hygiene (WASH): Application in governance of decentralized wastewater treatment in India using a novel validation methodology. Frontiers in Environmental Science, 7, Article 198. doi.org/10.3389/fenvs.2019.00198

Onwuegbuzie, A. J., Dickinson, W. B., Leech, N. L., \& Zoran, A. G. (2009). A qualitative framework for collecting and analyzing data in focus group research. International Journal of Qualitative Methods, 8(3), 1-21. doi.org/10.1177/160940690900800301

Pouliotte, J., Smit, B., \& Westerhoff, L. (2009). Adaptation and development: Livelihoods and climate change in Subarnabad, Bangladesh. Climate and Development, 1(1), 31-46. doi.org/10.3763/cdev.2009.0001

Rabbani, G., Rahman, A., \& Mainuddin, K. (2013). Salinity-induced loss and damage to farming households in coastal Bangladesh. International Journal of Global Warming, 5(4). doi.org/10.1504/ijgw.2013.057284

Rauken, T., Mydske, K., \& Winsvold, M. (2015). Mainstreaming climate change adaptation at the local level. Local Environment, 20(4), 408-423. doi.org/10.1080/13549839.2014. 880412

Rodima-Taylor, D., Olwig, M. F., \& Chhetri, N. (2011). Adaptation as innovation, innovation as adaptation: An institutional approach to climate change. Applied Geography, 33, 107-111. doi.org/10.1016/j.apgeog.2011.10.011

Saha, D., Hossain, S., Mondal, M. S., \& Rahman, R. (2016). Agricultural adaptation practices in coastal Bangladesh: Response to climate change impacts. In Journal of Modern Science and Technology, 4(1), 63-74. zantworldpress.com/product-single/?poId= 3813\&pageId $=3800$

Sallu, S. M., Twyman, C., \& Stringer, L. C. (2010). Resilient or vulnerable livelihoods? Assessing livelihood dynamics and trajectories in rural Botswana. Ecology and Society, 15(4), Article 3. doi.org/10.5751/ES-03505-150403

Schiffer, E., \& Hauck, J. (2010). Net-Map: Collecting social network data and facilitating network learning through participatory influence network mapping. Field Methods, 22(3), 231-249. doi.org/10.1177/1525822X10374798 
Scott, J., \& Carrington, P. J. (Eds.). (2011). The SAGE handbook of social network analysis. SAGE Publications.

Shameem, M. I. M., Momtaz, S., \& Rauscher, R. (2014). Vulnerability of rural livelihoods to multiple stressors: A case study from the southwest coastal region of Bangladesh. Ocean \& Coastal Management, 102(Part A), 79-87. doi.org/10.1016/ J.OCECOAMAN.2014.09.002

Tauhid Ur Rahman, M., Rasheduzzaman, M., Habib, M. A., Ahmed, A., Tareq, S. M., \& Muniruzzaman, S. M. (2017). Assessment of fresh water security in coastal Bangladesh: An insight from salinity, community perception and adaptation. Ocean \& Coastal Management, 137, 68-81. doi.org/10.1016/j.ocecoaman.2016.12.005

Thomas, D. S. G., Twyman, C., Osbahr, H., \& Hewitson, B. (2007). Adaptation to climate change and variability: Farmer responses to intra-seasonal precipitation trends in South Africa. Climatic Change, 83(3), 301-322. doi.org/10.1007/s10584-006-9205-4

Uddin, M., Bokelmann, W., \& Entsminger, J. (2014). Factors affecting farmers' adaptation strategies to environmental degradation and climate change effects: A farm level study in Bangladesh. Climate, 2(4), 223-241. doi.org/10.3390/cli2040223

Wang, D. J., Shi, X., McFarland, D. A., \& Leskovec, J. (2012). Measurement error in network data: A re-classification. Social Networks, 34(4), 396-409. doi.org/10.1016/ j.socnet.2012.01.003

Yu, W. H., Alam, M., Hassan, A., Saleh Khan, A., Ruane, A. C., Rosenzweig, C., Major, D. C., \& Thurlow, J. (2010). Climate change risks and food security in Bangladesh. Earthscan. doi.org/10.4324/9781849776387

Zeller, M., Feulefack, J., \& Neef, A. (2006, August 12-18). How accurate is participatory wealth ranking (PWR) in targeting the poor? A case study from Bangladesh [Conference paper]. International Association of Agricultural Economists-2006 Annual Meeting, Queensland, Australia. doi.org/10.22004/ag.econ.25237 
This text is taken from Human Ecology Review, Volume 26, Number 2, 2020, published by ANU Press, The Australian National University, Canberra, Australia. doi.org/10.22459/HER.26.02.2020.07 